\title{
OS CURSOS DE EDUCAÇÃO E FORMAÇÃO COMO UMA RESPOSTA AO INSUCESSO E ABANDONO ESCOLAR: ESTUDO REALIZADO NA REGIÃO DOURO SUL ${ }^{1}$
}

\author{
José Patrício ${ }^{2}$ Célia Ribeiro ${ }^{3}$
}

\begin{abstract}
Resumo: Os Cursos de Educação e Formação (CEF) surgiram como uma medida para o combate ao insucesso e ao abandono escolar, proporcionando aos jovens percursos escolares $e$ de formação que facilitem a construção de projectos profissionais mais de acordo com os seus interesses e expectativas, possibilitando assim a conclusão da escolaridade obrigatória.

$O$ presente estudo foi realizado em 14 escolas dos 10 concelhos pertencentes à Região Douro Sul, em que foram inquiridos 235 professores e 544 alunos.

Os resultados obtidos levaram-nos a concluir que os CEF são realmente uma resposta para o combate ao insucesso e abandono escolar nesta região, pois numa população de 601 alunos matriculados no ano lectivo de 2008/2009 e dos 544 alunos inquiridos, $260(47.79 \%)$ responderam que se não frequentassem um CEF já teriam abandonado a escola e 503 (92.50\%) afirmaram que os seus resultados escolares melhoraram com a frequência de um CEF.
\end{abstract}

Palavras-chave: Escola; Educação e Formação; Insucesso Escolar; Abandono Escolar

1 Este artigo é parte integrante da Dissertação de Mestrado em Ciências da Educação, Especialização em Administração e Organização Escolar, apresentada ao Centro Regional das Beiras da Universidade Católica Portuguesa.

${ }^{2}$ Mestre em Ciências da Educação, Especialização em Administração e Organização Escolar, pelo Centro Regional das Beiras da Universidade Católica Portuguesa.

${ }^{3}$ Professora Auxiliar do Departamento de Economia Gestão e Ciências Sociais do Centro Regional das Beiras da Universidade Católica Portuguesa. E-mail: cribeiro@crb.ucp.pt 
Abstract: Educational and Training Courses as a response to Academic Failure and Dropout: Study conducted in the Southern Douro Region.

The Educational and Training Courses (CEF) emerged as a way to combat academic failure and school dropout, by offering young people academic and training choices that make it easier for them to follow career paths more in line with their interests and expectations, thus allowing them to complete their mandatory education.

This study was performed in 14 schools in the 10 municipalities belonging to the Southern Douro Region, in which 235 teachers and 544 students were interviewed.

The results obtained allowed us to conclude that the CEF are a real response to combat academic failure and dropout in this region, since in a population of 601 students registered in the academic year 2008/2009 and of the 544 students interviewed, 260 (47.79\%) responded that if they had not attended a CEF, they would have already dropped out of school and 503 (92.50\%) stated that their grades improved after attending a CEF.

Keywords: School; Education and Training; Academic Failure; School Dropout

\section{INTRODUÇÃO}

Num mundo em rápida mutação, que se repercute em todos os domínios da vida política, económica, social e cultural, o futuro dos nossos jovens está hoje dependente, cada vez mais, da sua educação e formação, que se tornaram assim as prioridades decisivas deste início de século.

Todos os anos, segundo dados do Ministério da Educação, "abandonam o sistema de ensino sem qualquer qualificação, escolar ou profissional, mais de 90000 portugueses" (Azevedo, 2001, p. 149).

Perante este "desperdício" ou "mortalidade escolar" (Azevedo, 2001, p. 151), urge criar medidas que possam alterar esta situação, desenvolvendo mecanismos que permitam que o sistema de ensino se torne educativo também para aqueles que "não aprendem bem ou dentro do ritmo médio" (p. 154).

Foi com base nesta situação, que o XV Governo Constitucional entendeu dar prioridade à tomada de medidas que visem, de forma sistémica, a promoção do sucesso escolar e a prevenção dos diferentes tipos de abandono escolar (Despacho Conjunto n. ${ }^{\circ}$ 453/2004, de 27 de Julho).

Para dar resposta ao elevado número de jovens em situação de abandono escolar, que entram precocemente no mercado de trabalho com níveis de formação escolar e profissional muito baixos, surge a iniciativa Novas Oportunidades lançada pelo Ministério da Educação e Ministério do Trabalho e Solidariedade Social, que cria os Cursos de Educação e Formação (CEF), através 
do Despacho Conjunto n. ${ }^{\circ}$ 453/2004, de 27 de Julho. Esta medida enquadra-se nas políticas da União Europeia e insere-se no quadro das respostas nacionais aos objectivos definidos entre outros, na Estratégia de Lisboa, no Plano Nacional de Emprego e também no Plano Nacional de Prevenção do Abandono Escolar.

Face ao exposto, o presente estudo foi orientado pelos seguintes objectivos: analisar a variedade de ofertas profissionais nos CEF, nas 14 escolas dos 10 concelhos da Região do Douro Sul; identificar o que os alunos mais e menos gostam nos CEF; verificar se os resultados escolares dos alunos melhoraram ao frequentarem um CEF; identificar quais as escolas onde mais alunos afirmam que abandonavam a escola se não frequentassem um CEF; verificar se os professores consideram que os CEF promovem o sucesso escolar; e identificar quais os aspectos mais e menos positivos dos CEF, do ponto de vista dos professores.

\section{Os Cursos de Educação e Formação (CEF)}

Os CEF destinam-se preferencialmente a jovens com idade igual ou superior a 15 anos, em risco de abandono escolar ${ }^{4}$ ou que já abandonaram antes da conclusão da escolaridade dos 12 anos, bem como àqueles que, após conclusão dos 12 anos de escolaridade, não possuindo uma qualificação profissional, pretendam adquiri-la para ingresso no mundo de trabalho.

Estes cursos visam preparar os jovens para ingressar no mercado de trabalho com a escolaridade obrigatória e com qualificação profissional; proporcionar aos jovens sem escolaridade obrigatória percursos escolares e de formação que facilitem a construção de projectos profissionais mais de acordo com os seus interesses e expectativas; assegurar a todos os jovens até aos 18 anos de idade, que se encontrem ou não em situação de trabalho, a obtenção de níveis crescentes de escolaridade e certificação profissional (Cf. Quadro 1). São desenvolvidos pela rede de escolas públicas, particulares e cooperativas, escolas profissionais e outras entidades formadoras acreditadas em articulação com entidades da

${ }^{4} \mathrm{O}$ problema do abandono escolar tem suscitado nas ultimas décadas grande preocupação junto de governantes e da opinião pública em geral, sendo reconhecido como um problema simultaneamente social e institucional. Por outro lado, a comunidade científica portuguesa, e citando autores como, João Joaquim Antunes (1987, 1989), Ana Benavente (1994), Joaquim Azevedo (2001) e mais recentemente, Belmira Ferreira (2006) e José Canavarro (2007), entre outros, tem demonstrado que se trata de um processo multidimensional, resultado de um conjunto de causas, nomeadamente do próprio insucesso escolar, da família, da escola e tem como consequência imediata o handicap em termos de competências pessoais, profissionais e sociais, e implicações ao nível da integração social e profissional. 
comunidade, designadamente os órgãos autárquicos, as empresas ou organizações empresariais, outros parceiros sociais e associações de âmbito local ou regional.

Quadro 1 - Tipologia dos cursos e destinatários

\begin{tabular}{|c|c|c|c|}
\hline $\begin{array}{l}\text { Tipo } \\
\text { de } \\
\text { curso }\end{array}$ & Destinatários & $\begin{array}{c}\text { Duração } \\
\text { (horas) }\end{array}$ & Certificação \\
\hline Tipo 1 & $\begin{array}{l}\text { Jovens com habilitação inferior } \\
\text { ao } 6^{\circ} \text { ano, em risco de abandono } \\
\text { com duas ou mais retenções. }\end{array}$ & $\begin{array}{l}\text { Até } 2 \\
\text { anos } \\
1125 \mathrm{~h} \\
\end{array}$ & $\begin{array}{l}6^{\circ} \text { Ano de escolaridade } \\
\text { Qualificação Profissional de Nível } 1 .\end{array}$ \\
\hline Tipo 2 & $\begin{array}{l}\text { Jovens em risco de abandono } \\
\text { que completaram o } 6^{\circ} \text { ano ou } \\
\text { frequentaram com ou sem } \\
\text { aproveitamento o } 7^{\circ} \text { ano, ou } \\
\text { ainda que frequentaram o } 8^{\circ} \text { ano, } \\
\text { sem aproveitamento. }\end{array}$ & $\begin{array}{l}\text { Dois anos } \\
2109 \mathrm{~h}\end{array}$ & $\begin{array}{l}9^{\circ} \text { Ano de escolaridade } \\
\text { Qualificação Profissional de Nível } 2 .\end{array}$ \\
\hline Tipo 3 & $\begin{array}{l}\text { Jovens em risco de abandono, } \\
\text { com aproveitamento no } 8^{\circ} \text { ano, } \\
\text { ou com frequência, sem } \\
\text { aproveitamento do } 9^{\circ} \text { ano de } \\
\text { escolaridade. }\end{array}$ & $\begin{array}{l}\text { Um ano } \\
1200 \mathrm{~h}\end{array}$ & $\begin{array}{l}9^{\circ} \text { Ano de escolaridade } \\
\text { Qualificação Profissional de Nível } 2 .\end{array}$ \\
\hline Tipo 4 & $\begin{array}{l}\text { Jovens que concluíram o } 9^{\circ} \text { ano } \\
\text { ou que apresentaram uma ou } \\
\text { mais repetências no ensino } \\
\text { secundário, frequentaram sem } \\
\text { concluir qualquer curso de nível } \\
\text { secundário de educação ou } \\
\text { equivalente, e que pretendam no } \\
\text { imediato concretizar um projecto } \\
\text { profissional. }\end{array}$ & $\begin{array}{l}\text { Um ano } \\
1230 \mathrm{~h}\end{array}$ & $\begin{array}{l}\text { Certificado de competências escolares } \\
\text { Qualificação Profissional de Nível } 2 .\end{array}$ \\
\hline Tipo 5 & Jovens titulares de curso tipo 4. & $\begin{array}{l}\text { Dois anos } \\
2276 \mathrm{~h}\end{array}$ & $\begin{array}{l}12^{\circ} \text { Ano de escolaridade } \\
\text { Qualificação Profissional de Nível } 3\end{array}$ \\
\hline Tipo 6 & $\begin{array}{l}\text { Jovens com o } 11^{\circ} \text { ano de } \\
\text { escolaridade com } \\
\text { aproveitamento ou frequência do } \\
12^{\circ} \text { ano, sem aproveitamento. }\end{array}$ & $\begin{array}{l}\text { Um ano } \\
\text { ou } \\
\text { superior } \\
1425 \mathrm{~h}\end{array}$ & $\begin{array}{l}12^{\circ} \text { Ano de escolaridade } \\
\text { Qualificação Profissional de Nível } 3\end{array}$ \\
\hline Tiро 7 & $\begin{array}{l}\text { Jovens titulares de um curso } \\
\text { científico-humanístico, ou } \\
\text { equivalente, do nível secundário } \\
\text { de educação, que pertença à } \\
\text { mesma área de formação afim } \\
\text { àquela em que se integra a } \\
\text { qualificação visada pelo curso a } \\
\text { frequentar. }\end{array}$ & $\begin{array}{l}\text { Um ano } \\
1155 \mathrm{~h}\end{array}$ & Qualificação Profissional de Nível 3 \\
\hline
\end{tabular}

Fonte: Despacho Conjunto $n^{\circ} 453 / 2004$, de 27 de Julho.

Nota: Poderá ser autorizada pelo Director Regional, a frequência dos cursos por alunos com idade inferior a 15 anos. 
Como se pode observar pelo quadro 1, existem sete tipos de CEF, que conferem diferentes níveis de escolaridade e tipos de qualificação e certificação profissional. Quanto à estrutura curricular, esta acentua a componente profissionalizante, adequada aos níveis de qualificação visados e tendo em conta as especificidades das respectivas áreas de formação, e compreendem as seguintes componentes de formação:

a) Componente de formação sócio-cultural

b) Componente de formação científica

c) Componente de formação tecnológica

d) Componente de formação prática

Observando os quadros 2 e 3, podemos ver as componentes de formação, assim como as áreas de competências e as respectivas disciplinas /domínios/ unidades de formação, com a correspondente carga horária semanal de 31.5 horas que equivale a 21 blocos ( 1 bloco $=90$ minutos).

Quadro 2 - Desenho curricular do CEF Tipos 1, 2 e 3

\begin{tabular}{|l|l|l|}
\hline $\begin{array}{c}\text { Componente } \\
\text { de } \\
\text { Formação }\end{array}$ & Áreas de competências & $\begin{array}{l}\text { Disciplinas/domínios/unidade } \\
\text { de formação }\end{array}$ \\
\hline $\begin{array}{l}\text { Sócio- } \\
\text { cultural }\end{array}$ & $\begin{array}{l}\text { Línguas, cultura e } \\
\text { comunicação }\end{array}$ & $\begin{array}{l}\text { Língua Portuguesa } \\
\text { Língua Estrangeira } \\
\text { Tecnologias de Informação e } \\
\text { Comunicação }\end{array}$ \\
\cline { 2 - 4 } & Cidadania e sociedade & $\begin{array}{l}\text { Cidadania e Mundo Actual } \\
\text { Higiene, Saúde e Segurança no } \\
\text { Trabalho } \\
\text { Educação Física }\end{array}$ \\
\hline Científica & Ciências aplicadas & $\begin{array}{l}\text { Matemática Aplicada } \\
\text { Disciplina Específica }\end{array}$ \\
\hline Tecnológica & Tecnologias Específicas & $\begin{array}{l}\text { Unidade do itinerário de } \\
\text { qualificação associado }\end{array}$ \\
\hline Prática & \multicolumn{2}{|l|}{ Estágio em contexto de trabalho } \\
\hline
\end{tabular}

Fonte: Portaria n. ${ }^{\circ} 118 / 2005$, de 14 de Outubro. 
Quadro 3 - Desenho curricular do CEF Tipos 4, 5, 6, 7 e curso de formação complementar

\begin{tabular}{|l|l|l|}
\hline $\begin{array}{l}\text { Componente } \\
\text { de Formação }\end{array}$ & Áreas de competências & $\begin{array}{l}\text { Disciplinas/domínios/unidade } \\
\text { de formação }\end{array}$ \\
\hline Sócio-cultural & $\begin{array}{l}\text { Línguas, cultura e } \\
\text { comunicação }\end{array}$ & $\begin{array}{l}\text { Língua Portuguesa } \\
\text { Língua Estrangeira } \\
\text { Tecnologias de Informação e } \\
\text { Comunicação }\end{array}$ \\
\cline { 2 - 3 } & Cidadania e sociedade & $\begin{array}{l}\text { Cidadania e Mundo Actual } \\
\text { Higiene, Saúde e Segurança no } \\
\text { Trabalho } \\
\text { Educação Física }\end{array}$ \\
\hline Científica & Ciências aplicadas & $\begin{array}{l}\text { Disciplinas de Ciências } \\
\text { Aplicadas } \\
\text { Disciplina Específica 1 } \\
\text { Disciplina Específica 2 } \\
\text { Disciplina Específica 3 }\end{array}$ \\
\hline Tecnológica & Tecnologias Específicas & $\begin{array}{l}\text { Unidade do itinerário de } \\
\text { qualificação associado }\end{array}$ \\
\hline Prática & Estágio em contexto de trabalho \\
\hline
\end{tabular}

Fonte: Portaria n. ${ }^{\circ} 118 / 2005$, de 14 de Outubro.

$\mathrm{O}$ acesso dos candidatos aos cursos de educação e formação tem por base um processo de orientação escolar e profissional a desenvolver pelos centros de apoio sócio-educativo (CASE) e pelos serviços de psicologia e orientação (SPO) dos estabelecimentos de ensino básico e secundário para os cursos desenvolvidos no âmbito do Ministério da Educação e pelos centros de emprego. Os Conselhos de Turma também podem referenciar alunos que demonstrem perfil para este tipo de cursos.

A avaliação é contínua e reveste um carácter regulador, proporcionando um reajustamento do processo de ensino-aprendizagem e o estabelecimento de um plano de recuperação que permita a apropriação pelos alunos/formandos de métodos de estudo e de trabalho e proporcione o desenvolvimento de atitudes e de capacidades que favoreçam uma maior autonomia na realização das aprendizagens.

Para a conclusão, com aproveitamento de um CEF, é necessário reunir as seguintes condições:

- Cursos tipo 1, 2 ou 3, os alunos/formandos terão que obter uma classificação final igual ou superior ao nível 3 em todas as componentes de formação e na Prova de Avaliação Final (PAF), nos cursos que a integram.

- Cursos tipo 4, 5, 6 e 7, os alunos/formandos terão que obter uma classificação final igual ou superior a 10 valores em todas as disciplinas e ou 
domínios e ou módulos, nomeadamente no estágio e na Prova de Avaliação Final.

O prosseguimento dos estudos é possível quando os alunos/formandos obtêm uma certificação escolar do $9^{\circ}$ ano, desde que realizem exames nas disciplinas de Língua Portuguesa e Matemática, de acordo com as condições estabelecidas no Decreto-Lei n. . 209/2002, de 17 de Outubro, que aprova a organização curricular do ensino básico, estabelecendo os princípios orientadores da organização e da gestão curricular desse nível de ensino, bem como da avaliação das aprendizagens e do processo de desenvolvimento do currículo nacional.

A formação obtida pelos alunos com frequência sem conclusão de um curso do tipo 1 ou 2 é creditada, a pedido dos interessados, através da análise curricular, para efeitos de prosseguimento de estudos.

A formação obtida pelos alunos sem conclusão de um curso do tipo 5 é creditada, a pedido dos interessados, através da análise curricular, para efeitos de prosseguimento de estudos noutras ofertas formativas de nível secundário.

O prosseguimento de estudos de nível superior por parte de alunos que obtenham, através de cursos de educação e formação a certificação escolar do $12^{\circ}$ ano de escolaridade obriga à realização de exames finais nacionais em condições análogas às estabelecidas para os cursos profissionais de nível secundário de educação, bem como ao cumprimento dos demais requisitos previstos na regulamentação de acesso ao ensino superior.

Tendo como base documentos publicados pelo GEPE, constata-se que no ano lectivo 2006/2007 estavam matriculados em Cursos de Educação e Formação, 29947 alunos, distribuídos pelas várias escolas públicas e privadas, conforme se observa no quadro 4.

Quadro 4 - Número de alunos matriculados em CEF, no ano lectivo 2006/2007

\begin{tabular}{|c|c|c|c|c|c|}
\hline $\begin{array}{c}\text { Nível de } \\
\text { Ensino }\end{array}$ & $\begin{array}{c}\text { Escolas } \\
\text { Públicas }\end{array}$ & $\begin{array}{c}\text { Escolas } \\
\text { Privadas }\end{array}$ & Homens & Mulheres & Total \\
\hline $2^{\circ}$ Ciclo & 515 & 116 & 474 & 157 & 631 \\
\hline $3^{\circ}$ Ciclo & 20129 & 4289 & 16189 & 8229 & 24418 \\
\hline Secundário & 3628 & 1270 & 2743 & 2155 & 4898 \\
\hline
\end{tabular}

Fonte: GEPE, 2006/2007.

\section{Metodologia}

\section{Contextualização do estudo}

A Região Douro Sul, onde o presente estudo foi realizado, encontra-se integrada na zona Norte de Portugal conforme podemos verificar na figura 1. 
Figura 1 - Mapa da Zona Norte de Portugal

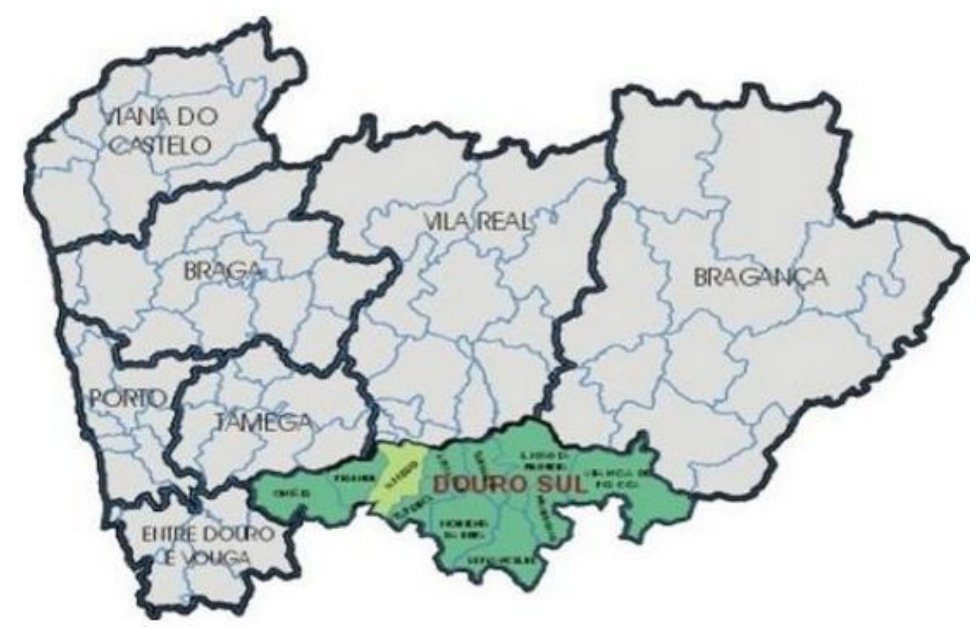

Fonte: INE, 2006.

É constituída por 10 concelhos situados ao longo da margem esquerda do rio Douro, Armamar, Cinfães, Lamego, Moimenta da Beira, Penedono, Resende, São João da Pesqueira, Sernancelhe, Tabuaço e Tarouca (Figura 2).

\section{Figura 2 - Mapa da Região Douro Sul}

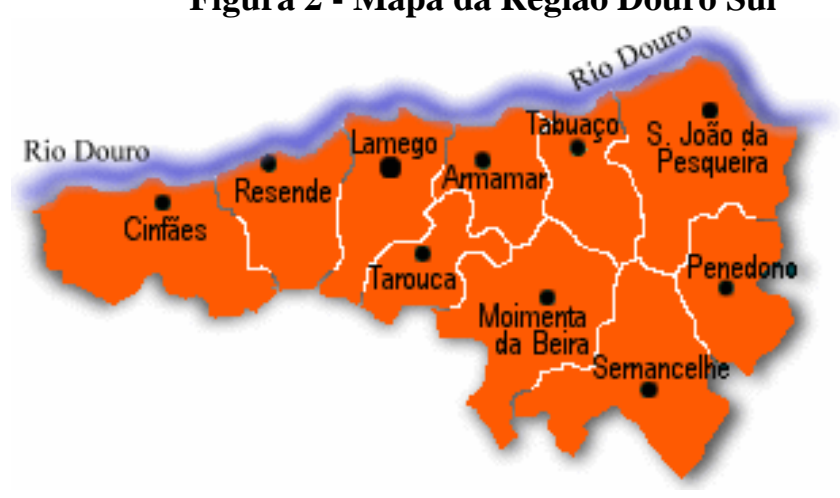

Fonte: INE, 2006.

No quadro seguinte constatamos que quatro dos 10 concelhos desta região possuem uma área superior a $200 \mathrm{Km}^{2}$, dos quais se salientam Cinfães, 
Moimenta da Beira, S. J. Pesqueira e Sernancelhe. No entanto, quando comparámos estes valores com os dados relativos à população correspondente, apuramos que a maior densidade populacional verifica-se na cidade de Lamego, também apelidada de capital do Douro Sul (Cf. Quadro 5).

\begin{tabular}{|c|c|c|c|c|c|}
\hline \multirow[b]{3}{*}{ Concelho } & dro 5 & ea e pop & lação da $\mathbf{R}$ & gião Dou & \\
\hline & \multicolumn{2}{|c|}{ Área } & \multicolumn{3}{|c|}{ População } \\
\hline & $\begin{array}{l}\text { Área } \\
\left(\mathrm{km}^{2}\right)\end{array}$ & $\begin{array}{l}\text { Perímetro } \\
(\mathbf{K m})\end{array}$ & Habitantes* & $\begin{array}{c}\text { Alunos * } \\
\text { Matriculados }\end{array}$ & $\begin{array}{l}\text { Tx Crescimento } \\
\text { efectivo }(\%)\end{array}$ \\
\hline Armamar & 117.2 & 61 & 7217 & 901 & -0.72 \\
\hline Cinfães & 239.3 & 93 & 20774 & 3432 & -1.35 \\
\hline Lamego & 165.4 & 82 & 26484 & 5275 & -1.09 \\
\hline $\begin{array}{c}\text { Moimenta da } \\
\text { Beira }\end{array}$ & 220 & 88 & 11030 & 2311 & -0.13 \\
\hline Penedono & 133.7 & 64 & 3346 & 444 & -0.63 \\
\hline Resende & 123.4 & 58 & 11775 & 2135 & -0.95 \\
\hline S.J. Pesqueira & 266.1 & 100 & 8202 & 1408 & -0.83 \\
\hline Sernancelhe & 228.6 & 99 & 6104 & 869 & -0.47 \\
\hline Tabuaço & 133.9 & 70 & 6359 & 921 & -1.25 \\
\hline Tarouca & 100.1 & 73 & 8357 & 1351 & 0.43 \\
\hline Total & & & 109648 & 19047 & \\
\hline
\end{tabular}

Fonte: INE, 2002; * GEPE, 2006/2007.

Mediante o quadro apresentado, podemos ainda certificar que a taxa de crescimento efectivo desta região tem vindo a evoluir desfavoravelmente, isto é, tem vindo a diminuir a sua população, à excepção do concelho de Tarouca. Esta situação é o reflexo dos problemas de fixação populacional do interior do país em geral.

Quanto aos alunos matriculados no ano lectivo 2006/2007, verifica-se um total 19047, situando-se o maior número nos concelhos de Lamego e Cinfães.

O quadro 6 apresenta o número de alunos matriculados em cada um dos 10 concelhos, segundo o nível de Ensino Básico e Ensino Secundário, no ano lectivo 2006/2007. 
Quadro 6 - Alunos matriculados por concelho segundo o nível de ensino básico e secundário no ano lectivo 2006/2007

\begin{tabular}{|c|c|c|c|c|}
\hline \multirow{2}{*}{$\begin{array}{c}\text { Concelhos do } \\
\text { Douro Sul }\end{array}$} & \multicolumn{3}{|c|}{ Ensino Básico } & \multirow{2}{*}{$\begin{array}{c}\text { Ensino } \\
\text { Secundário }\end{array}$} \\
\cline { 2 - 4 } & $\mathbf{1}^{\mathbf{0}}$ Ciclo & $\mathbf{2}^{\mathbf{0}}$ Ciclo & $\mathbf{3}^{\mathbf{0}}$ Ciclo & 0 \\
\hline Armamar & 300 & 170 & 243 & 432 \\
\hline Cinfães & 1049 & 564 & 929 & 938 \\
\hline Lamego & 1234 & 641 & 1013 & 393 \\
\hline Moimenta da Beira & 523 & 297 & 524 & 0 \\
\hline Penedono & 146 & 91 & 131 & 367 \\
\hline Resende & 618 & 322 & 561 & 283 \\
\hline S. J. Pesqueira & 391 & 198 & 319 & 155 \\
\hline Sernancelhe & 210 & 149 & 209 & 92 \\
\hline Tabuaço & 272 & 141 & 239 & 152 \\
\hline Tarouca & 427 & 207 & 363 & \\
\hline
\end{tabular}

Fonte: Anuário Estatístico da Região Norte, INE, 2008.

Analisando o quadro 7, podemos verificar que os valores relativos à retenção e desistência são bastante elevados no Ensino Básico sobretudo no $3^{\circ}$ ciclo e com destaque nos concelhos de Tabuaço, Tarouca, S.J. Pesqueira e Cinfães, onde rondam os $24 \%$, isto é um quarto da população.

$\mathrm{O}$ concelho que apresenta uma taxa de retenção e desistência mais baixo no ensino básico é Moimenta da Beira (7.4\%), seguido de Armamar (7.9\%). 


\section{Quadro 7 - Taxas de retenção e desistência no Ensino Básico e Taxa de transição/conclusão do Ensino Secundário}

\begin{tabular}{|c|c|c|c|c|c|c|c|}
\hline \multirow{2}{*}{$\begin{array}{c}\text { Concelhos do Douro } \\
\text { Sul }\end{array}$} & \multicolumn{3}{|c|}{$\begin{array}{c}\text { Taxa retenção e desistência no } \\
\text { Ensino Básico \% }\end{array}$} & \multicolumn{3}{c|}{$\begin{array}{c}\text { Taxa de transição/conclusão do } \\
\text { Ensino Secundário\% }\end{array}$} \\
\cline { 2 - 8 } & Total & $\begin{array}{c}\mathbf{1}^{\mathbf{0}} \\
\text { Ciclo }\end{array}$ & $\begin{array}{c}\mathbf{2}^{\mathbf{0}} \\
\text { Ciclo }\end{array}$ & $\begin{array}{c}\mathbf{3}^{\mathbf{0}} \\
\text { Ciclo }\end{array}$ & Total & C. G* & C. Tec** \\
\hline Armamar & 7.9 & 4.7 & 2.9 & 16.2 & 65.6 & 64.7 & 73.7 \\
\hline Cinfães & 13.5 & 5.0 & 13.5 & 24.6 & 74.9 & 72.1 & 85.5 \\
\hline Lamego & 10.3 & 2.7 & 8.8 & 21.4 & 75.2 & 75.9 & 70.8 \\
\hline Moimenta da Beira & 7.4 & 1.1 & 3.7 & 18.1 & 77.9 & 78.2 & 76.1 \\
\hline Penedono & 13.5 & 4.1 & 18.7 & 21.4 & 77.9 & 78.2 & 76.1 \\
\hline Resende & 10.1 & 5.5 & 4.7 & 18.8 & 80.1 & 77.8 & 91.7 \\
\hline S. J. Pesqueira & 13.1 & 6.1 & 12.6 & 24.1 & 70.7 & 70.7 & 65.2 \\
\hline Sernancelhe & 10.4 & 6.2 & 12.2 & 13.7 & 70.7 & 70.7 & 65.2 \\
\hline Tabuaço & 12.3 & 2.2 & 11.3 & 26.9 & 68.8 & 68.8 & 65.2 \\
\hline Tarouca & 15.1 & 6.8 & 15.5 & 24.8 & 77.6 & 79.5 & 50.0 \\
\hline
\end{tabular}

Fonte: Anuário Estatístico da Região Norte, INE, 2008.

Nota: * Cursos Gerais/Científicos - Humanísticos; ** Cursos Tecnológicos

\section{População e amostra}

A população-alvo abrangeu todos os alunos e professores distribuídos pelas 14 escolas dos 10 concelhos da Região Douro Sul, que frequentam e ministram CEF. No ano lectivo de 2008/2009, este estudo incidiu sobre uma população de 601 alunos e 277 professores.

Analisando o quadro 8, verificamos que é na Escola EB 2,3 de Cinfães e na Escola ES/3 de Resende que há mais alunos matriculados nos CEF, respectivamente 94 e 70. Se analisarmos por concelho, constatamos que Cinfães tem 149 alunos matriculados, divididos pelas escolas EB 2,3 de Cinfães (94 alunos); ES/3 de Cinfães (55 alunos) e EB 2,3 de Souselo (51 alunos) e Lamego com 83, distribuídos pelas escolas EB 2,3 (15 alunos), ES/3 da Sé (10 alunos) e ES/3 Lamego (58 alunos), todas na cidade. 
Quadro 8 - Escolas, alunos, professores e tipos de CEF, no ano lectivo 2008/2009

\begin{tabular}{|c|c|c|c|c|}
\hline Escola & $\begin{array}{l}\text { Número } \\
\text { de CEF }\end{array}$ & $\begin{array}{c}\text { Alunos } \\
\text { Matriculados / } \\
\text { Inquiridos }\end{array}$ & $\begin{array}{l}\text { Professores } \\
\text { Inquiridos }\end{array}$ & Designação do curso \\
\hline EB 2,3 Armamar & 2 & $26 / 23$ & 12 & $\begin{array}{l}\text { Jardinagem } \\
\text { Produção Agrícola }\end{array}$ \\
\hline EB 2,3 Cinfães & 7 & $94 / 85$ & 21 & $\begin{array}{l}\text { Cozinha (3) } \\
\text { Moda } \\
\text { Mecânica } \\
\text { Bar e Mesa } \\
\text { Jardinagem }\end{array}$ \\
\hline ES/3 Cinfães & 3 & $55 / 51$ & 17 & $\begin{array}{l}\text { Padaria e pastelaria } \\
\text { Operador de informática } \\
\text { Tapeçaria }\end{array}$ \\
\hline EB 2,3 Souselo & 4 & $51 / 47$ & 30 & $\begin{array}{l}\text { Apoio à família } \\
\text { Pintura C. Civil } \\
\text { Informática } \\
\text { Jardinagem }\end{array}$ \\
\hline EB 2,3 Lamego & 1 & $15 / 13$ & 9 & Azulejaria \\
\hline $\begin{array}{l}\text { Ag. Vert. Sé } \\
\text { Lamego }\end{array}$ & 1 & $10 / 10$ & 10 & Empregado comercial \\
\hline ES/ 3 Lamego & 4 & $58 / 50$ & 31 & $\begin{array}{l}\text { Operador de fotografia } \\
\text { Electromecânico de } \\
\text { electrodomésticos } \\
\text { Cabeleireiro de senhoras } \\
\text { Pasteleiro/ padeiro }\end{array}$ \\
\hline $\begin{array}{l}\text { ES/3 Moimenta } \\
\text { da Beira }\end{array}$ & 3 & $50 / 34$ & 22 & $\begin{array}{l}\text { Canalizador } \\
\text { Operador de redes de } \\
\text { computador }(2)\end{array}$ \\
\hline EB 2,3 Penedono & 3 & $35 / 35$ & 12 & $\begin{array}{l}\text { Operador de informática } \\
\text { Cabeleireiro } \\
\text { Mesa e bar }\end{array}$ \\
\hline ES/3 Resende & 5 & $70 / 62$ & 21 & $\begin{array}{l}\text { Electricidade e instalações (2) } \\
\text { Jardinagem } \\
\text { Serviços comerciais }\end{array}$ \\
\hline $\begin{array}{l}\text { EB 2,3/S S.J. } \\
\text { Pesqueira }\end{array}$ & 2 & $23 / 22$ & 8 & $\begin{array}{l}\text { Electricidade } \\
\text { Informática }\end{array}$ \\
\hline $\begin{array}{l}\text { EB 2,3 } \\
\text { Sernancelhe }\end{array}$ & 4 & $44 / 44$ & 12 & $\begin{array}{l}\text { Tec. Electricidade } \\
\text { Tec. Informática } \\
\text { Serviço de mesa } \\
\text { Mecânico }\end{array}$ \\
\hline EB 2,3/S Tabuaço & 2 & $30 / 28$ & 15 & $\begin{array}{l}\text { Jardinagem } \\
\text { Mesa e Bar }\end{array}$ \\
\hline EB 2,3/S Tarouca & 3 & $40 / 40$ & 15 & $\begin{array}{l}\text { Jardinagem } \\
\text { Cozinha } \\
\text { Apoio familiar e à } \\
\text { comunidade } \\
\end{array}$ \\
\hline Total & 44 & $601 / 544$ & 235 & \\
\hline
\end{tabular}


As ofertas profissionais mais frequentes são jardinagem/espaços verdes e informática, a que se seguem cozinha, bar e mesa e electricidade. É também de realçar a existência de opções profissionais em áreas pouco comuns, como seja a moda, a tapeçaria, a azulejaria e a fotografia.

\title{
Amostras
}

\begin{abstract}
Alunos
O total de alunos matriculados nos CEF nas 14 escolas dos 10 concelhos da Região do Douro Sul é de 601, sendo que 544 foram os inquiridos, o que corresponde a $90.52 \%$, sendo que 192 são do sexo feminino (35.3\%) e 352 do sexo masculino (64.7\%).

A média de idade dos inquiridos é 16 anos com 35.5\%, seguindo 17 anos com $22.8 \%$ e 15 anos com 21.0\%. As idades mais baixa e mais alta são, respectivamente, 13 anos ( 3 alunos) e 20 anos ( 2 alunos).

Todos os alunos inquiridos frequentam o terceiro ciclo do ensino básico.
\end{abstract}

\section{Professores}

Verifica-se uma população de 277 professores que leccionam nos CEF nas 14 escolas dos concelhos da Região do Douro Sul, responderam ao inquérito 235, o que corresponde a $84.83 \%$, sendo que 146 são do sexo feminino e 89 são do sexo masculino.

A média de idades dos professores inquiridos é 36 anos, verifica-se que o mais novo tem 22 e o mais velho tem 64 anos.

Em termos de habilitações literárias, verifica-se que a maioria dos professores possui licenciatura $(\mathrm{n}=202 ; 86.0 \%), 6.0 \%(\mathrm{n}=14)$ bacharelato, $5.0 \% \quad(\mathrm{n}=12)$ mestrado e $3.0 \%$ ( $n=7)$ são técnicos com Certificado de Aptidão Profissional (CAP).

Em termos de tempo de serviço, a média dos professores da amostra é de 10 anos, constata-se que há 7 professores com zero anos de tempo de serviço, ou seja, que estão a leccionar pela primeira vez, e um docente que já lecciona há 36 anos.

De todos os professores que constituem a amostra, 183 leccionam CEF de nível 2, ou seja, CEF frequentado por jovens em risco de abandono que completaram o $6^{\circ}$ ano ou frequentaram com ou sem aproveitamento o $7^{\circ}$ ano, ou ainda que frequentaram o $8^{\circ}$ ano, sem aproveitamento e 50 leccionam CEF de nível 3, ou seja, frequentado por alunos em risco de abandono, com aproveitamento no $8^{\circ}$ ano, ou com frequência, sem aproveitamento, do $9^{\circ}$ ano de escolaridade. 


\section{Instrumentos de Investigação}

Foram elaborados dois questionários, um destinado aos alunos e outro aos professores. O questionário destinado aos alunos tem, na primeira parte, três questões referentes à caracterização dos inquiridos, a segunda parte tem seis questões relativas à temática em estudo.

Igualmente, o questionário construído e aplicado aos professores tem na primeira parte seis questões relativas à caracterização dos inquiridos, e na segunda parte oito questões alusivas à temática em investigação.

\section{Resultados}

Analisando as respostas dos alunos, verificamos que dos 544 alunos inquiridos, apenas $17(3,1 \%)$ responderam que não gostam de frequentar CEF, enquanto que a grande maioria, 527 afirmam que gostam, o que corresponde a $96.9 \%$.

Analisando as respostas sobre os aspectos que os alunos mais gostam no CEF, verifica-se que as quatro respostas mais referenciadas são as seguintes, por ordem decrescente (Cf. Gráfico 1): de aprender a fazer coisas práticas $(83.6 \%)$, de no final do curso ficar com um diploma de Formação Profissional (61.2\%), de fazer uma aprendizagem numa área profissional (51.5\%), de fazer um estágio numa empresa $(44.7 \%)$.

\section{Gráfico 1 - O que mais gostas no CEF?}

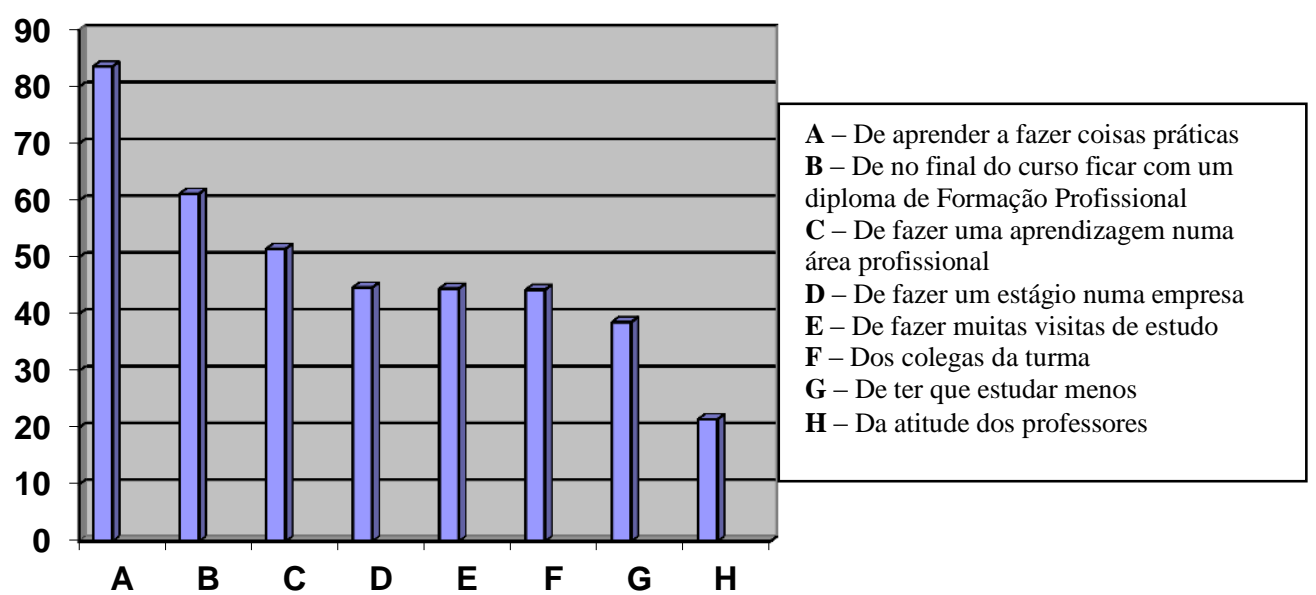

Entre os quatro aspectos que os alunos referem gostar menos, destacam-se (Cf. Gráfico 2): ter poucas aulas práticas $(62.1 \%)$, fazerem poucas visitas de 
estudo (59.2\%), terem falta de materiais para trabalhar a parte profissional (58.3\%), do estágio profissional durar pouco tempo (50.2\%).

\section{Gráfico 2 - O que menos gostas no CEF?}

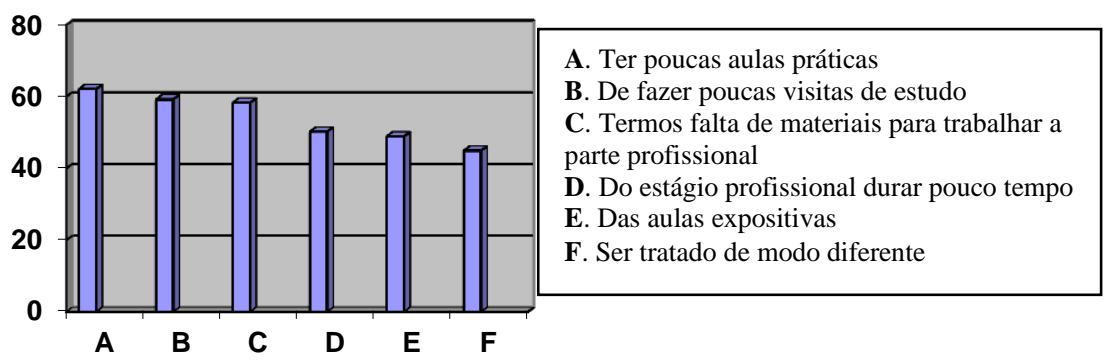

Quando confrontados com a questão: se não estivesses num CEF já terias abandonado a escola, verifica-se que $47.9 \%$ dos alunos respondem sim, o que corresponde a 260 alunos e $52.1 \%$ responde não, o que corresponde a 283 alunos e há um aluno, $0.18 \%$, que não responde.

Analisando as respostas por escola, verifica-se que é nas escolas da Sé de Lamego, Tarouca, S.J. Pesqueira e Resende, que encontramos o maior número de alunos que respondem que se não frequentassem o $\mathrm{CEF}$ já teriam abandonado a escola (Cf. Quadro 9).

Quadro 9 - O abandono dos alunos dos CEF por escola

\begin{tabular}{|l|l|c|c|c|c|c|}
\hline $\mathbf{N}^{\mathbf{0}}$ & \multicolumn{1}{|c|}{ Escola } & Alunos & Sim & $\mathbf{\%}$ & Não & \% \\
\hline 1 & EB 2,3 de Armamar & 23 & 9 & 39.1 & 14 & 60.9 \\
\hline 2 & EB 2,3 de Cinfães & 85 & 41 & 48.2 & 44 & 51.8 \\
\hline 3 & ES/3 de Cinfães & 51 & 16 & 31.4 & 35 & 68.6 \\
\hline 4 & EB 2,3 de Souselo & 47 & 15 & 31.9 & 32 & 68.1 \\
\hline 5 & EB 2,3 de Lamego & 10 & 8 & $\mathbf{8 0}$ & 2 & 20 \\
\hline 6 & A.V Sé de Lamego & 50 & 22 & 44 & 28 & 56 \\
\hline 7 & ES/3 Latino de Lamego & 34 & 13 & 38.2 & 21 & 61.8 \\
\hline 8 & EB S/3 de Moimenta da Beira & 35 & 14 & 40 & 21 & 60 \\
\hline 9 & EB 2,3 de Penedono & 62 & 36 & $\mathbf{5 8}$ & 26 & 42 \\
\hline 10 & ES/3 de Resende & 21 & 14 & $\mathbf{6 6 . 7}$ & 7 & 33.3 \\
\hline 11 & EB 2,3/S S.J.Pesqueira * & 44 & 23 & $\mathbf{5 2 . 3}$ & 21 & 47.7 \\
\hline 12 & EB 2,3 de Sernancelhe & 28 & 15 & $\mathbf{5 3 . 6}$ & 13 & 46.4 \\
\hline 13 & EB 2,3/S de Tabuaço & 40 & 31 & $\mathbf{7 7 . 5}$ & 9 & 22.5 \\
\hline 14 & EB 2,3/S de Tarouca & $\mathbf{5 4 3}$ & $\mathbf{2 6 0}$ & $\mathbf{4 7 . 9}$ & $\mathbf{2 8 3}$ & $\mathbf{5 2 . 1}$ \\
\hline & Total & & & & \\
\hline
\end{tabular}

* 1 aluno não respondeu $(0.2 \%)$. 
Analisando os resultados obtidos dos 544 inquiridos quanto aos resultados escolares, verifica-se que 503 são unânimes em afirmar que os seus resultados escolares melhoraram com a frequência do CEF, o que corresponde a $92.5 \%$ dos alunos. Apenas 41 (7.5\%) referem que não.

Quando questionados se sentem "tratados de modo diferente pelos professores, auxiliares de acção educativa e colegas", verifica-se que dos 544 alunos, $147(27.0 \%)$ referem que se sentem tratados de modo diferente pelos professores, 121 de forma positiva, 26 de forma negativa.

Em termos de auxiliares de acção educativa, 136 alunos (25,0\%) responderam que sim, 83 pela positiva (realçam aspectos positivos), 50 pela negativa e 3 não especificam.

No que concerne aos colegas, $158(29,0 \%)$ responderam que se sentem tratados de modo diferente, 111 pela positiva, 38 pela negativa e 9 não especificam.

O gráfico seguinte compara a percepção que os alunos têm sobre o modo como são "tratados" tanto pelos professores, como pelos auxiliares e colegas, onde se pode verificar que os alunos sentem-se tratados de modo diferente, mas pela positiva, isto é, referem atitudes positivas que os vários actores educativos têm para com eles, como seja, dar-lhes atenção, gostar deles, respeitá-los, ajudálos, e valorizá-los (Cf. Gráfico 3).

Há alguns alunos que apesar de responderem que se sentem tratados de modo diferente, não especificam se é por atitudes mais ou menos positivas.

\section{Gráfico 3 - Sentes-te tratado de modo diferente?}

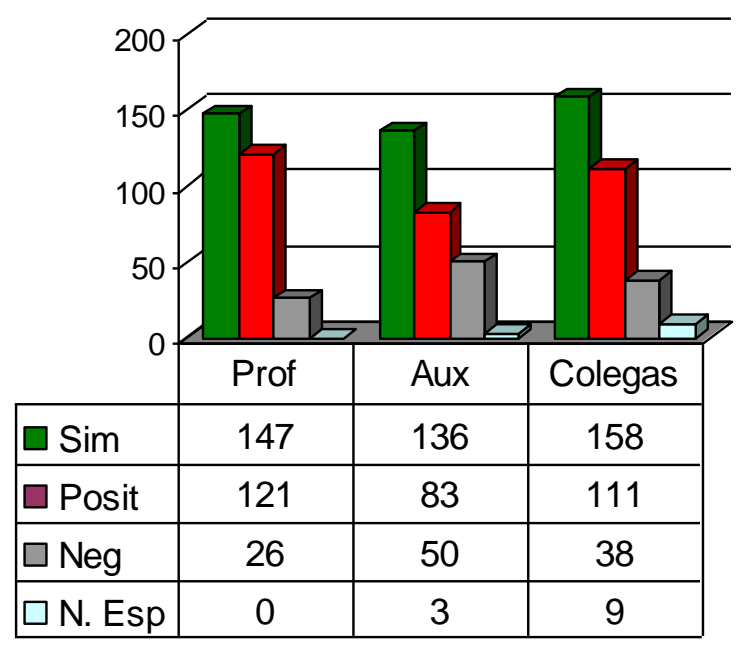


Analisando os resultados dos questionários aplicados aos professores, verifica-se que a maioria dos inquiridos lecciona CEF há 1 e há 2 anos (Cf. Quadro 10).

Quadro 10 - Número de anos que os professores leccionam CEF

\begin{tabular}{|c|c|c|}
\hline $\mathbf{N}^{\mathbf{0}}$ de anos & $\mathbf{n}$ & \% \\
\hline 0 & 8 & 3.4 \\
\hline 1 & 77 & 32.8 \\
\hline 2 & 81 & 34.5 \\
\hline 3 & 44 & 18.7 \\
\hline 4 & 20 & 8.5 \\
\hline 5 & 5 & 2.1. \\
\hline Total & $\mathbf{2 3 5}$ & $\mathbf{1 0 0 . 0}$ \\
\hline
\end{tabular}

Analisando as respostas obtidas à questão: gosta de leccionar CEF, verifica-se que a maioria dos professores, 154 (65.5\%), manifesta que sim, embora haja um número considerável, 77 (32.8\%) professores inquiridos, que não gosta de leccionar CEF, os restantes não respondem.

Também constatamos que dos 77 professores que responderam que não gostam de leccionar CEF, 60 são do sexo feminino, o que corresponde a 77.9\%.

Analisando a questão: é professor nos CEF por vontade própria ou do órgão de gestão da escola, verificamos que a maioria dos professores lecciona nos CEF por decisão do órgão de gestão da escola, o que corresponde a $76.6 \%$.

Quando questionamos sobre se os CEF contribuem para a diminuição do abandono escolar, verificamos que 205 professores, isto é, $87.2 \%$ respondem afirmativamente. E sobre se os CEF promovem o sucesso escolar, constata-se que $63.4 \%$ também respondem afirmativamente.

Analisando os quatro aspectos mais positivos que os professores consideram nos CEF, verificamos que a maioria sugere o facto de possibilitarem a conclusão da escolaridade obrigatória a alunos com dificuldades de aprendizagem. $\mathrm{O}$ quadro 11, apresenta os aspectos mais positivos mencionados pelos professores.

\section{Quadro 11 - Aspectos mais positivos nos CEF}

\begin{tabular}{|l|c|c|}
\hline \multicolumn{1}{|c|}{ Aspectos mais positivos } & n & \% \\
\hline $\begin{array}{l}\text { Possibilitam a conclusão da escolaridade obrigatória a alunos } \\
\text { com dificuldades de aprendizagem }\end{array}$ & 211 & 89.9 \\
\hline Permitem uma Formação Profissional & 169 & 72.3 \\
\hline $\begin{array}{l}\text { Desenvolvem nos alunos hábitos e atitudes que possibilitam } \\
\text { uma melhor inserção no mercado de trabalho }\end{array}$ & 116 & 49.4 \\
\hline São a resposta para a exclusão & 104 & 44.3 \\
\hline
\end{tabular}


Analisando o quadro sobre os aspectos menos positivos que os professores consideram nos CEF, a maioria refere o facto de haver demasiada tolerância para com estes alunos, nomeadamente em termos de comportamento. No quadro 12, são apresentados os aspectos menos positivos referidos pelos professores.

\section{Quadro 12 - Aspectos menos positivos nos CEF}

\begin{tabular}{|l|c|c|}
\hline \multicolumn{1}{|c|}{ Aspectos menos positivos } & n & \% \\
\hline $\begin{array}{l}\text { Haver demasiada tolerância para com estes alunos, } \\
\text { nomeadamente em termos de comportamento }\end{array}$ & 142 & 60.4 \\
\hline $\begin{array}{l}\text { A falta de condições nas escolas ao nível da componente } \\
\text { profissional }\end{array}$ & 134 & 57 \\
\hline $\begin{array}{l}\text { Estes alunos têm normalmente pouco acompanhamento por } \\
\text { parte dos Encarregados de Educação }\end{array}$ & 109 & 46.4 \\
\hline $\begin{array}{l}\text { Os referenciais de formação estão excessivamente desfasados } \\
\text { do perfil de alunos CEF }\end{array}$ & 96 & 40.9 \\
\hline
\end{tabular}

Como sugestões para a melhoria do funcionamento dos CEF nas escolas, os 83 docentes que se prenunciaram sobre esta questão sugeriram as propostas apresentadas no quadro 13. É de salientar o facto de a sugestão mais indicada pelos professores ser a necessidade de melhorar nas escolas as condições para o funcionamento da formação profissional.

\section{Quadro 13 - Sugestões para a melhoria do funcionamento dos CEF}

\begin{tabular}{|l|c|}
\hline \multicolumn{1}{|c|}{ Sugestões } & n \\
\hline Melhorar as condições para funcionamento da formação profissional nas escolas & 25 \\
\hline Adequar os currículos ao perfil dos alunos & 14 \\
\hline Maior controlo do comportamento dos alunos & 12 \\
\hline Aumentar a variedade de ofertas profissionais & 9 \\
\hline Maior responsabilização dos Encarregados de Educação & 8 \\
\hline Formação adequada dos professores & 8 \\
\hline Ter mais atenção ao perfil dos alunos para os CEF & 7 \\
\hline Maior exigência & 5 \\
\hline Ter atenção à falta de material & 4 \\
\hline Maior rigor nos sistema de avaliação e controlo de faltas & 4 \\
\hline Envolver mais os alunos & 4 \\
\hline Falta de manuais de apoio & 4 \\
\hline Reavaliar o sistema de funcionamento dos CEF & 3 \\
\hline Fazer turmas mais pequenas & 3 \\
\hline Diminuir a burocracia & 2 \\
\hline A formação ser mais prática & 2 \\
\hline Dar mais valor a estes cursos & 2 \\
\hline Retirar os CEF das escolas regulares e criarem estruturas de raiz para o efeito & 1 \\
\hline Escolher as equipas pedagógicas & 1 \\
\hline Existirem na equipa profissionais de apoio como psicólogos & 1 \\
\hline
\end{tabular}


Em síntese, tendo em conta a dimensão da amostra estudada, 544 alunos, que corresponde a $90.52 \%$ da população existente, conclui-se que devido a esta modalidade de ensino é possível manter na escola 259 alunos, o que é bastante significativo em termos de combate ao abandono escolar.

Por outro lado, ao ficarem na escola, estes alunos, não só terão a oportunidade de concluir a escolaridade obrigatória como de receber um certificado de formação profissional, o que constitui uma mais valia para um futuro ingresso no mercado de trabalho. Além disto, a manutenção destes alunos na escola contribui também para criar mais postos de trabalho para docentes e pessoal não docente, assim como estratégia para neutralizar possíveis flagelos sociais, como seja, o consumo de drogas, a delinquência, etc., que se traduzem em exclusão social.

Quanto aos 235 professores inquiridos, 154, ou seja, 65.5\% afirmam que gostam de leccionar nos CEF. Entre os 77 docentes que responderam que não gostam de leccionar CEF, 60 são do sexo feminino.

A grande maioria dos professores $(87.2 \%)$ é de opinião que os CEF contribuem para a diminuição do abandono escolar e (63.4\%) consideram que estes promovem o sucesso escolar.

$\mathrm{Na}$ última questão do questionário onde eram solicitadas aos professores sugestões para a melhoria do funcionamento dos CEF, talvez por ser uma questão aberta, foram apenas $83(35.3 \%)$ os inquiridos que responderam. No entanto, analisadas as respostas, verifica-se que as grandes preocupações dos docentes que leccionam os CEF focalizam-se sobretudo em três áreas: na escola, referindo a falta de condições de trabalho adequadas à vertente profissional, pouca variedade de ofertas profissionais, falta de materiais e a desadequação dos currículos; nos alunos, defendendo maior controlo no comportamento, mais rigor e exigência no sistema de avaliação e de faltas, dar mais atenção ao perfil dos alunos para estes cursos, o aumento do envolvimento dos discentes e maior responsabilização dos Encarregados de Educação; nos professores, mencionando a necessidade de formação adequada por parte dos docentes da área profissional e a falta de manuais e outros materias de apoio. 


\section{Conclusão}

Da reflexão produzida sobre esta problemática, duas ideias centrais sobressaem: a primeira é a da prevenção, ou seja, as dificuldades de aprendizagem reveladas pelos alunos devem ser identificadas o mais cedo possível no seu percurso escolar e alvo de intervenção pedagógica imediata, pois quanto mais precoce for o despiste e mais eficaz a resolução das dificuldades reveladas, menos necessário será, no futuro, recorrer a medidas compensatórias de duvidosa eficiência pedagógica, como a retenção. A segunda ideia central é a da implementação de estratégias pedagógicas alternativas.

Analisados os resultados obtidos nos questionários realizados aos alunos e professores envolvidos nos CEF da Região Douro Sul e partindo do nosso pressuposto de tentarmos saber se os CEF são uma das respostas para o insucesso e o abandono escolar e tendo ainda em conta os objectivos que definimos para esta investigação, é possível tirarmos algumas conclusões.

Em relação aos alunos é notório que a grande maioria tem uma visão positiva sobre os CEF, isto é, gostam de frequentar os cursos, sentem-se mais motivados para continuarem os estudos, obtêm maior aproveitamento escolar, reconhecem que se não fosse esta modalidade de ensino já teriam abandonado a escola, vêem nesta oferta a possibilidade de concluírem a escolaridade obrigatória com uma formação prática num determinado contexto profissional.

Analisando os aspectos que os alunos indicam como mais e menos positivos, sobressai de imediato o que os "atrai" nesta modalidade de ensino, é "o ser mais prático", isto é, ser uma aprendizagem baseada no "manusear", no fazer coisas concretas, práticas. Estamos, portanto, perante alunos para quem uma aula teórica "dita tradicional" diz pouco. São alunos capazes de adquirir e desenvolver grandes competências, mas especificamente direccionadas para situações práticas. E realmente se observarmos as 44 ofertas profissionais constatamos que são áreas onde são necessários alguns conceitos teóricos, mas afirmam-se sobretudo pela componente da experimentação, que desde as aulas práticas, passando pelos estágios, são a grande atracção deste tipo de ensino. 


\section{Bibliografia}

ANTUNES, J, J. (1989). Os abandonos escolares no ensino básico - uma fábrica de novos desfavorecidos - o meio rural e o meio urbano. Porto: Edições ASA.

ANTUNES, J. J. (1987). Os abandonos escolares no ensino básico. In E. Pires et al. (Coord.). O ensino básico em Portugal (pp. 97-132). Porto: Edições ASA.

ANUÁRIO ESTATÍSTICO DA REGIÃO NORTE (2008). Instituto Nacional de Estatística.

AZEVEDO, J. (2001). Avenidas de liberdade - Reflexões sobre a política educativa ( $3^{\text {a }}$ Edição). Porto: Edições ASA.

BENAVENTE, A.; Campiche, J.; Seabra, T.; e Sebastião, J. (1994). Renunciar à escola. $O$ abandono escolar no ensino básico. Lisboa: Fim de Século Edições, Lda.

CANAVARRO, J. (2007). Para a compreensão do abandono escolar. Lisboa: Texto Editores.

FERREIRA, C. B. (2006). Orientação vocacional com alunos com elevado risco de abandono escolar. Consultado em 03/12/2009. Disponível em www.Psicologia.com.pt/artigos/textos

INE (2002). Censos 2001 - Resultados definitivos do XIV Recenseamento Geral da População. Lisboa.

\section{Legislação}

Decreto-Lei n. ${ }^{\circ}$ 209/2002, de 17 de Outubro

Despacho Conjunto n. $.^{\circ} 453 / 2004$, de 27 de Julho, rectificado por Rectificação n ${ }^{\circ}$ 1673/2004, de 7 de Setembro

Portaria n. ${ }^{\circ} 118 / 2005$, de 14 de Outubro

\section{Sites}

http://www.dren.min-edu.pt

http://www.gepe.min-edu.pt/

http://www.iefp.pt

http://www.ine.pt 